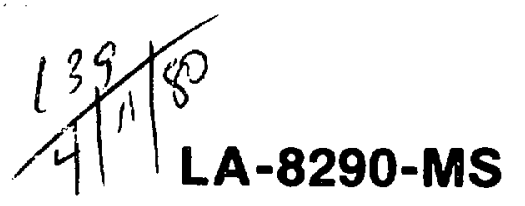

Informal Report

\section{Longitudinal Capture in the Radio-Frequency-Quadrupole Structure}

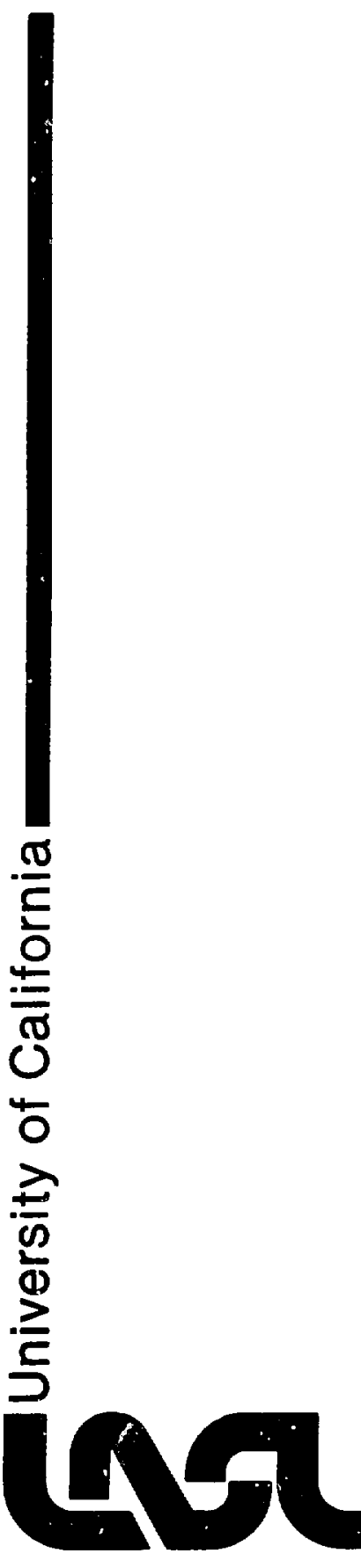

\title{
MASTER
}


LONGITUDINAL CAPTURE IN THE RADIO-FREQUENCY-QUADRUPOLE STRUCTURE

by

\title{
Shigemi Inagaki
}

\begin{abstract}
The radio-frequency-quadrupole ( $R F Q$ ) linac structure not only can attain easily transverse focusing in the low-beta region, but also can obtain very high capture efficiency because of its low beta-lambda and low-particle rigidity. An optimization study of the zero space-charge longitudinal capture in an RFQ linac that yields configurations with large capture efficiency is described.
\end{abstract}

\section{INT RODUCTION}

In 1956 , Ia. B. Fainberg ${ }^{1}$ proposed an alternating-phase-focusing (APF) structure to obtain longitudinal and transverse stability without using foils, grids, or external focusing methods. However, the APF structure received little attention because it has a narrow stability region in a simple FoDo arrangement until D. A. Swenson of the Los Alamos Scientific Laboratory (LASL) adapted a low-energy APF section into the Pion Generator for Medical Irradiations (PIGMI) program. ${ }^{2}$ In the early 1960s, G. M. Anisimov and V. A. Teplyakov ${ }^{3}$ proposed giving up axial symmetry to provide alternating focusing. F. Fer et $a 1 .^{4}$ reported the results of APF field measurements for drift tubes having rectangular holes. Then a structure using gaps with a horn was built. In 1969, I. M. Kapchskii and V. A. Teplyakov ${ }^{5}$ proposed to generate an $\mathrm{r} f$ field by a configuration of four conducting wires. Various versions included a four-chamber resonator, a double-H resonator, a four-vane cavity, and a cloverdeaf cavity. Comprehensive theoretical studies are reported in Refs. 6 and 7 . 
The USSR proposes to use this structure in an intense neutron generator linac. ${ }^{8}$ In the first stage of the Russian URAL-15 accelerator, which will be used as a proton synchroton injector at the Institute of High Energy Physics, the double-H resonator structure will accelerate protons from $0.1 \mathrm{MeV}$ to $1.97 \mathrm{MeV} .^{9}$

In 1978, the Accelerator Technology Division at LASL did comprehensive studies $^{10}$ for a radio-frequency-quadrupole (RFO) structure for the Hanford Engineering Development Laboratory (HEDL) linac for the Fusion Materials Irradiation Testing (FMIT) Facility. Some recent LASL studies are reported in Refs. 11-13.

These studies indicate that the injection energy can be reduced significantly to as $10 \mathrm{w}$ as $50 \mathrm{kV}$ at $440 \mathrm{MHz}$ for protons. In this case the first cell length, which is defined as $\beta \lambda / 2$, is $3.52 \mathrm{~mm}$. Another advantage is that the RFQ structure can function as a buncher. The synchronous phase angle can be set at $-90^{\circ}$ in the injector and increased gradually until it becomes a constant value, for instance, $-30^{\circ}$ for a conventional drift-tube linac. Also, the field strength can be changed to give a good capture efficiency. This paper describes the RFQ optimization procedure and the results obtained from a computer study of longitudinal capture efficiency.

\section{LONGITUDINAL OSCILLATION}

The longitudinal oscillation equation for a linac is

$\frac{d}{d z}\left[\gamma_{s}^{3} \beta_{s}^{3} \frac{d}{d z}\left(\psi-\psi_{s}\right)\right]=-\frac{2 \pi}{\lambda} \cdot \frac{e}{m_{0} c^{2}}\left[E_{z}(r, z, t)-E_{z}\left(r, z, t_{s}\right)\right]$,

where $\gamma$ is the particle energy, $\beta$ is the particle velocity, $\psi$ is the particle phase, $\lambda$ is the wavelength of the electromagnetic field, e is the electric charge of the particle, $m_{0}$ is the rest mass, and $E$ is the electric field. The subscript $s$ denotes the synchronous particle. After some approximation Eq. (1) can be rewritten

$$
\frac{d^{2} x}{d l^{2}}=-n(\ell) x
$$


where

$x=\left(\psi-\psi_{s}\right)$

$d z=v_{s} d t_{s}=\beta_{s} \lambda d \ell$,

and

$\mathbf{n}=\frac{2 \pi e \lambda E_{0} T}{m_{0} c^{2} \gamma_{s}^{3}{ }_{B}}$,

where $v$ is the particle velocity, $n$ is the number of gaps, and $T$ is the transit time. The solution of Eq. (2) can be expressed by

$\mathrm{X}(\ell)=\mathrm{M}\left(\ell \mid \ell_{0}\right) \mathrm{X}\left(\ell_{0}\right)$,

where $X(\ell)$ is a vector matrix and $M\left(\ell \mid \ell_{0}\right)$ is a transform matrix with

$x(l)=\left[\begin{array}{c}x(l) \\ x^{\prime}(l)\end{array}\right]$,

$M\left(\ell \mid \ell_{0}\right)=\left[\begin{array}{ll}\cos \alpha & n^{-1 / 2} \sin \alpha \\ (-n)^{1 / 2} \sin \alpha & \cos \alpha\end{array}\right]$,

and

$\alpha=n^{1 / 2}\left(\ell-\ell_{0}\right)$

The rigidity $R, 2 \pi n^{-1 / 2}$, defines the $r f$ length that makes one oscillation period. For a proton accelerator with conventional parameters $\left(\psi_{s}=-30^{\circ}\right.$, 
$\mathrm{E}_{0}=1.5 \mathrm{MV} / \mathrm{m}, \mathrm{T}=0.8$, and $\left.\lambda=1.5 \mathrm{~m}\right), \mathrm{R}=16.2$ for a $750 \mathrm{keV}$ in jector or $R=8.2$ for a $50-\mathrm{keV}$ injector. The first cell length is $6 \mathrm{~cm}$ or $1.5 \mathrm{~cm}$, respectively. Therefore, if we choose any accelerating structure that has longitudinal and transverse stability at low injection energy, we can determine the dimensions of cells with a nonconstant synchronous phase to capture the beam efficiently. In most drift-tube linacs, the injection energy is either 500 or $750 \mathrm{keV}$ and the synchronous phase usually is maintained constant throughout the accelerator at approximately $-30^{\circ}$. We have made some trials to change the $-30^{\circ}$ value to improve the energy spectrum or the variation in mean energy. ${ }^{14-16}$ The capture efficiency, defined by $3 \psi_{s}$, was $25 \%$, and it increased to $60-70 \%$ by using a normal buncher.

In an RFQ structure, the injection energy can be reduced so significantly that the structure satisfies the requirements for short cell length and low rigidity, mentioned earlier. The synchronous phase at injection can be chosen to achieve $100 \%$ capture efficiency, that is, $\psi_{s}=-90^{\circ}$, then increased gradually to $-30^{\circ}$.

Using the approximation made by Kapchinsky, the spatial components of the potential and the electric field can be expressed as follows.

$U_{0}(r, \psi, z)=-\frac{v}{2}\left[\left(\frac{r}{R_{2}}\right)^{2} \cos 2 \psi+\frac{\left.a^{2}-1\right) I_{0}\left(k_{2} r\right)}{m^{2} I_{0}\left(k_{2} a\right)+I_{0}\left(k_{2} m a\right)} \sin k_{1} z\right]$,

$E_{0 r}=\frac{V}{2}\left[\frac{2 r}{R_{0}^{2}} \cos 2 \psi+\frac{\left(m^{2}-1\right) k_{2} I_{1}\left(k_{2} r\right)}{m^{2} I_{0}\left(k_{2} a\right)+I_{0}\left(k_{2} m a\right)} \sin k_{1} z\right]$,

$E_{0 \psi}=-v\left(\frac{r}{R_{0}}\right)^{2} \sin 2 \psi$,

$E_{0 z}=\frac{V}{2} \cdot \frac{\left(m^{2}-1\right) I_{0}\left(k_{2} r\right)}{m^{2} I_{0}\left(k_{2} a\right)+I_{0}\left(k_{2} m a\right)} k_{1} \cos k_{1} z$ 
where $a$ is the minimum distance between the electrode and the axis, $m$ is the modulation factor, $k_{1}=2 \pi / \beta \lambda$, and

$k_{2}=\left[\begin{array}{ll}\frac{2 \pi}{\lambda} & \frac{(2 l+1)^{2}}{\beta^{2}}-1\end{array}\right]^{1 / ?}$

The relationship between the rigidity $R_{0}$ and the distance $a$ is

$a=R_{0}\left[\frac{I_{0}\left(k_{2} a\right)+I_{0}\left(k_{2}{ }^{m a}\right)}{m^{2} I_{0}\left(k_{2} a\right) T I_{0}\left(k_{2} m a\right)}\right]^{1 / 2}$.

The energy gain per cell is

$\Delta W=e_{0} T L \cos \psi$,

with

$E_{0} T L=\frac{\pi}{4} \cdot \frac{V\left(m^{2}-1\right) I_{0}\left(k_{2} m a\right)}{m^{2} I_{0}\left(k_{2} a\right)+I_{0}\left(k_{2} m a\right)}$,

where $\mathrm{L}$ is the ceil length.

In our study, the values of $E_{0} T L$ and the synchronous phase $\psi_{s}$ are given as two functions. The energy gain and the phase advance are callculated in each cell for particles injected at all phases. We must find the two functions that bring the most particles together at the synchronous phase to obtain acceleration with minimum particle loss. After the values of $E_{0}$ T.L are found, we can find the appropriate values for a and $m$ using Eq. (17). However, we also must select these values to satisfy the transverse stability condition, which is not described here. The effects of space-charge are not included in this study. 
III. COMPUTATIONAL RESULTS

Figures $1(a)$ and $l(b)$ show the parameters for the synchronous phase and the electric field, respectively. The definitions of the terms are:

EHI is the horizontal intercept of the electric field function $(\mathrm{cm})$, EVI is the vertical intercept of the electric field function (MV/m), ESLI is the slope of the electric field function $(\mathrm{MV} / \mathrm{m} / \mathrm{cm})$, EUL is the upper limit of the electric field function (MV/cm), PHI is the horizontal intercept of the synchronous phase function (cm), PVI is the vertical intercept of the synchronous phase function (deg), PSLI is the slope of the synchronous phase function ( $\mathrm{deg} / \mathrm{cm}$ ), and PUL is the upper limit of the synchronous phase function (deg). To capture all the particles, PVI apparently should be $-90^{\circ}$. The PUL is $-30^{\circ}$, the same as that of a drift-tube linac so that the bucket area does not become too sma 11 and that the acceleration efficiency is tolerable. The PHI is essentially the length of the bunching section. We assumed the FVL to be $2 \mathrm{MV} / \mathrm{m}$. Several calculations showed that the application of an electric field at injection gives excess energy to some particles and allows them to escape the bucket. Therefore, the EVI was set at $0 \mathrm{MV} / \mathrm{m}$. The EHI was set at $0 \mathrm{~cm}$. Comprehensive variations of ESLI and PSLI were done for some bunching lengths ( $\mathrm{PHI}=0 \mathrm{~cm}, 20 \mathrm{~cm}$, or $40 \mathrm{~cm}$ ).

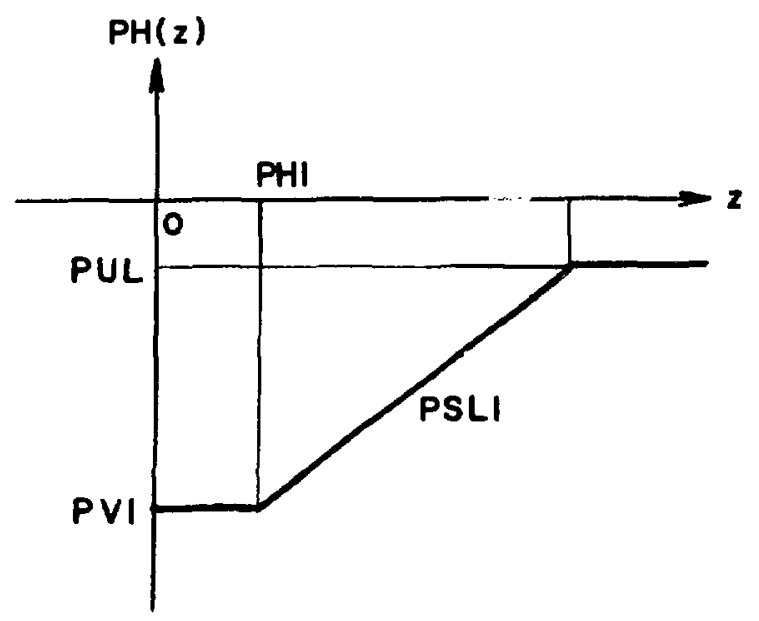

(a) synchronous phase

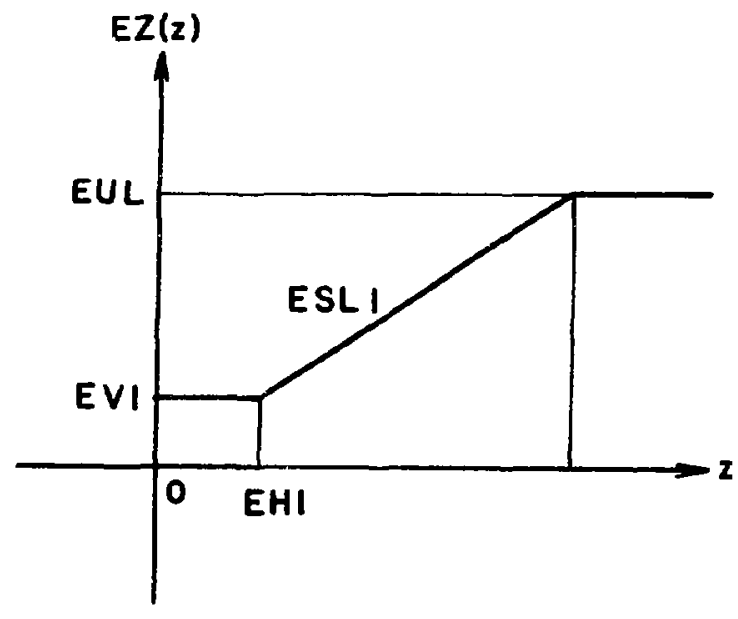

(b) electric field

Fig. 1. Phase and field variations along the $z$ axis. 
Our computer program consists of several subroutines: GENLIN, TRNSFM, EVBNCH, PLOT, PROF, PLTRMS, and others, and the functions EZ(z)and PH(z). Their definitions are:

GENLIN generates the cells of the linac that has a prefixed final energy for a given electric field function and a synchronous phase function;

TRNSFM computes the energy gains and the phase advances in the GENLIN cells for each injected particle;

EVBNCH evaluates the number of particles captured in 10-ft-wide bins by some energy spread, the mean phase, the mean energy, the root mean square in phase, and the root mean square in energy for the TRNSFM particles;

PLOT shows the phase-energy diagram for every NG cell as well as the energy and phase projection, shown Fig. 2;

PROF shows the phase oscillation and energy as well as the phase-space diagram at the end of the last cell, shown in Fig. 3;

PLTRMS shows the mean phase (PBAR), the root mean square phase (PRMS), the root mean square energy (WRMS), the length (LNGTH) at which the final energy is obtained, and the capture efficiency (APEF), as shown in Fig. 4;

$\mathrm{EZ}(z)$ is an electric field function; and

$\mathrm{PH}(\mathrm{z})$ is a synchronous phase function.

Figure 4 shows one of the results from the comprehensive phase and energy slope survey. The first line shows that the proton (PMU $=1.0$ ) is accelerated at $440.0 \mathrm{MHz}$ (FREQ $=440.0$ ) with an injection energy of $50 \mathrm{keV}$ $(W Z=0.05)$ to the final energy of $1 \mathrm{MeV}(W F=1.0)$. The second line shows the values for EHI, EVI, ESL, EUL, PHI, PVI, PSL, and PUL, respectively. For the electric slope (ESLI $=0.01 \mathrm{MV} / \mathrm{m} / \mathrm{cm}$ ), the synchronous phase slope is changed from $0.05^{\circ} / \mathrm{cm}$ to $1.0 \%$ cm in steps of $0.05 \% / \mathrm{cm}$ step. At the end of the linac PBAR, PRMS, and WRMS are shown by $x,+$, and $*$, respectively. Until PSLI $=0.35 \% \mathrm{~cm}$, the synchronous phase is changed so slowly that the mean phase does not reach $-30^{\circ}$. The sharp bending of LNGTH (*) at $0.1 \% / \mathrm{cm}$ shows that at these ESLI and PSLI values the final 1.0-MeV energy is not attained within the allowable number of cells the symbols $\odot, \odot, \square$, 


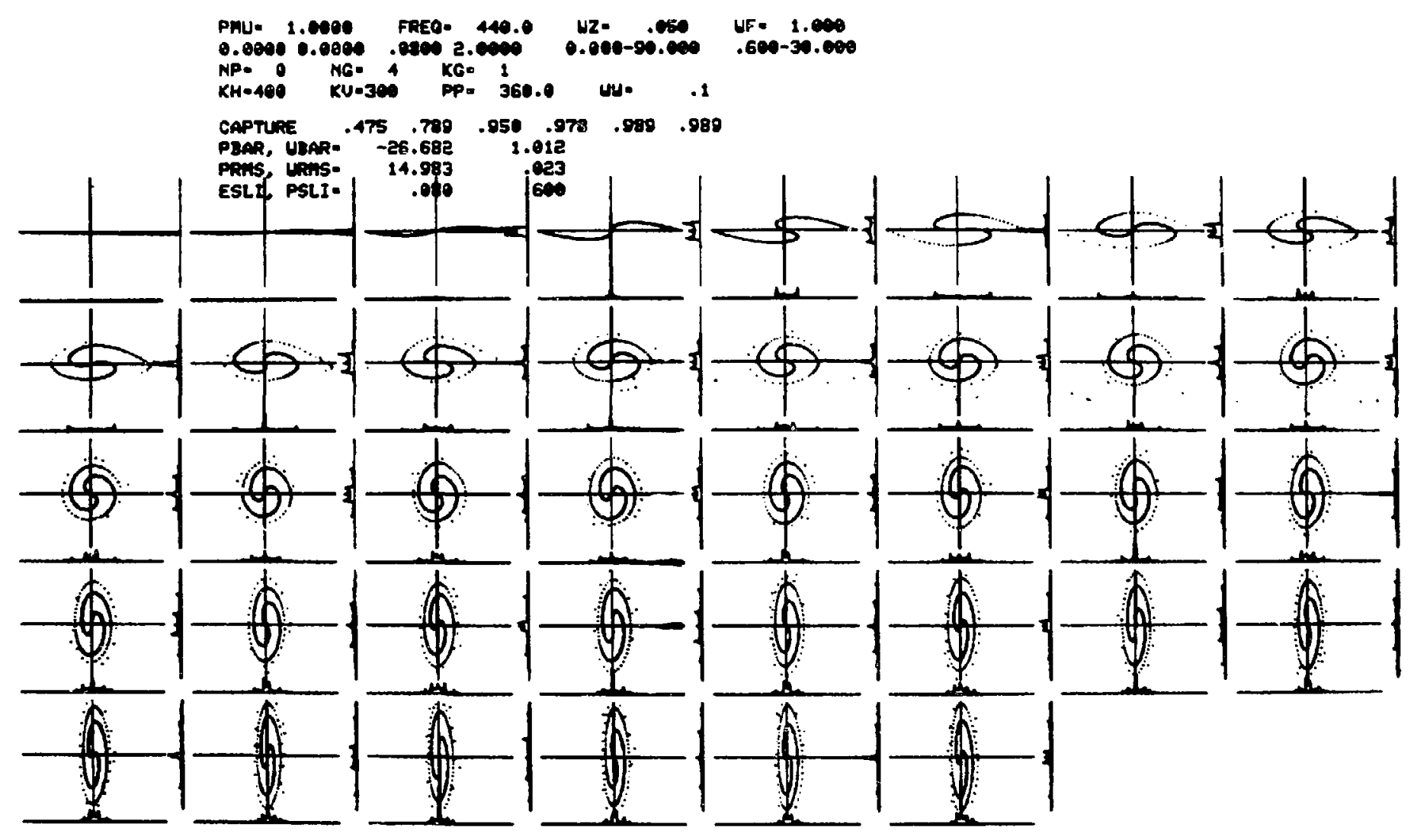

Fig. 2. Phase-energy plot. 


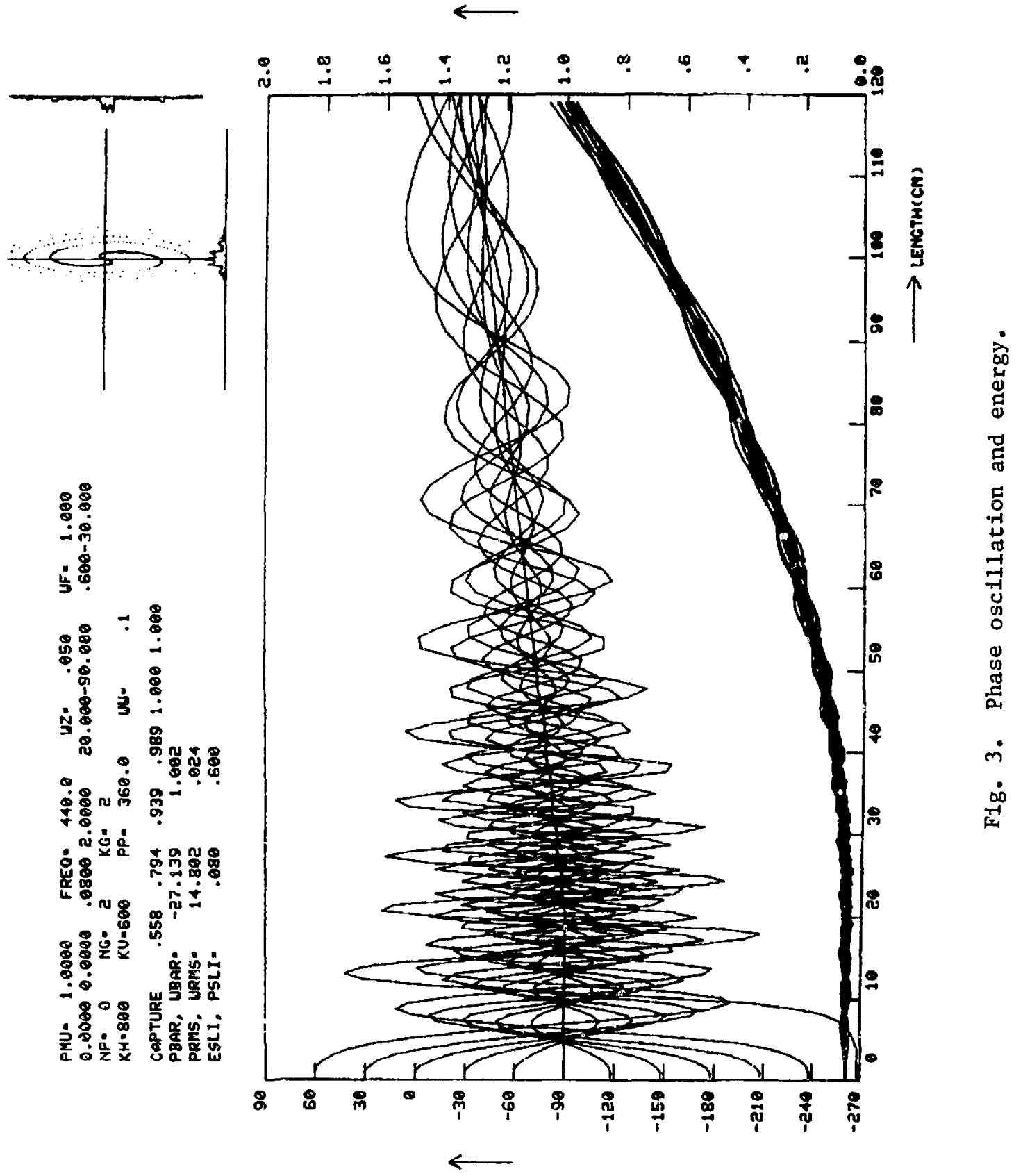




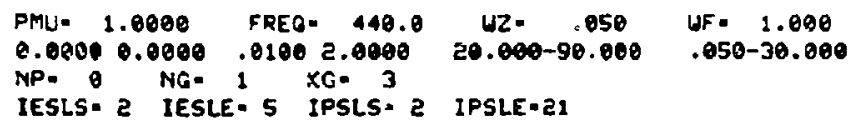

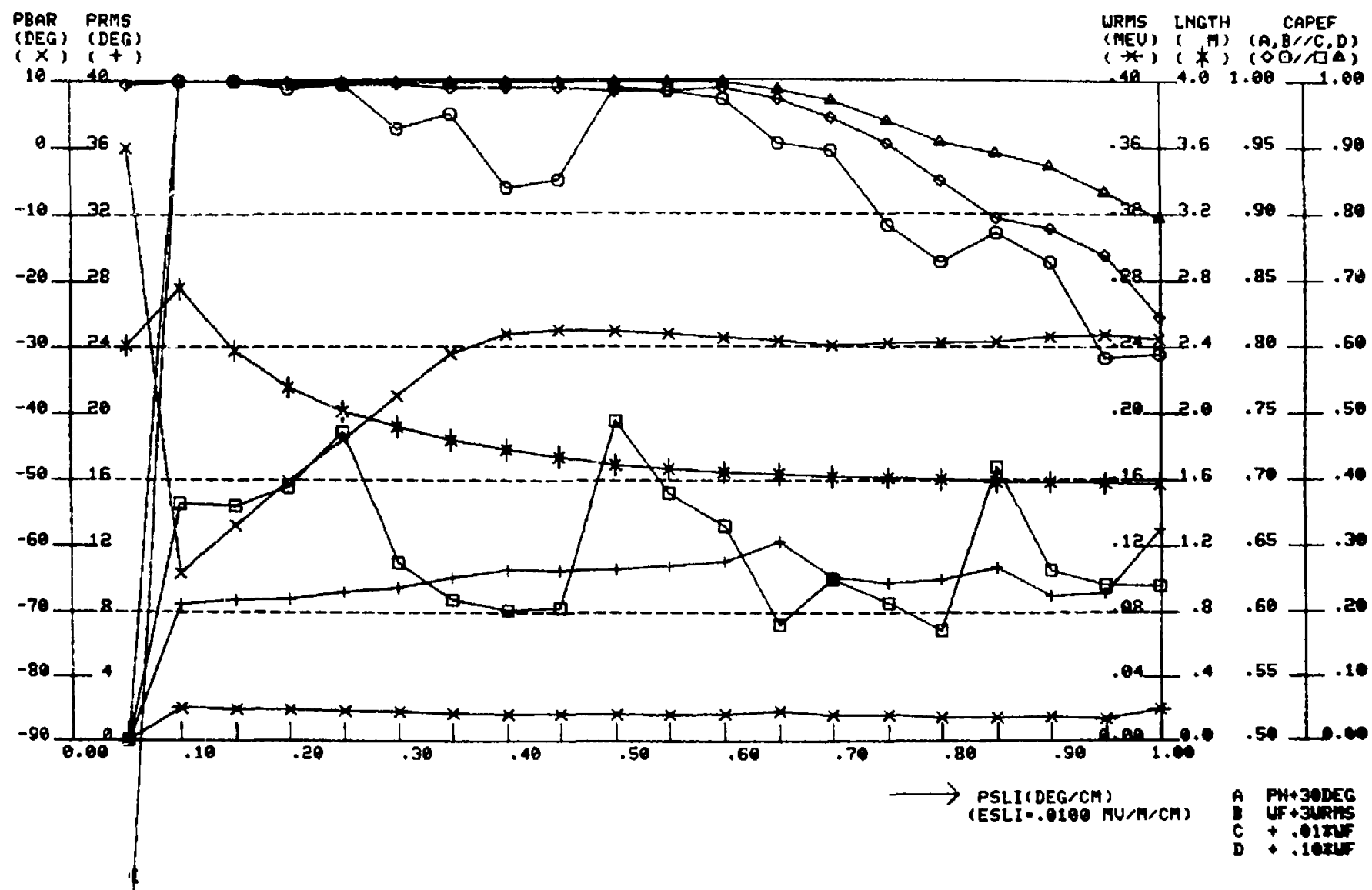

Fig. 4. Mean-phase, rms-phase, rms-energy, length, and capture efficiency graph. 
and $\triangle$ show the number of captured particles divided by the number of injected particles within $\left(\mathrm{PH} \pm 30^{\circ}\right),(\mathrm{WF} \pm 3$ WRMS $),( \pm 0.01 \mathrm{WF})$ and $( \pm 0.1 \mathrm{WF})$, respectively. If the particles pass through enough cells and experience several synchrotron oscillations, they will be bunched rather strongly resulting in good capture efficiency, as measured by $\left(\mathrm{PH} \pm 30^{\circ}\right)$. If the distribution is Gaussian, $99.7 \%$ of the particles are within \pm 3 rms and $95.4 \%$ within \pm 2 rms. Therefore, from (WF \pm 3 WRMS) w'e can determine the approximate spectrum. The term $(+0.01 \mathrm{WF})$ is a measure of how monoenergetic the spectrum is, but does not indicate the capture efficiency because the particles rotace within the bucket. The term $( \pm 0.1 \mathrm{WF})$ is a realistic energy spread and includes every particle captured in the initial acceleration, but it is possible also to count in lost particles at the final stage of acceleration and at the position where the field function changes from a constant slope to a constant value.

In some cases the capture efficiencies defined by $\left(\mathrm{PH} \pm 30^{\circ}\right)$ and ( $+0.1 \mathrm{WF})$ act the same and have the same numerical values. Figure 4 shows that to get $90 \%$ capture efficiency, any PSLI value can be taken from $0.1 \% / \mathrm{cm}$ to $0.8 \% \mathrm{~cm}$. The length of the linac then varies from $2.75 \mathrm{~m}$ to $1.6 \mathrm{~m}$. It is highty desirable to have a short linac length.

Figures 5, 6, and 7 show the capture efficiencies $( \pm 0.1 \mathrm{WF})$ and the length characteristic curves for $\mathrm{PHI}=0 \mathrm{~cm}, 20 \mathrm{~cm}$, or $40 \mathrm{~cm}$, respectively. The abcissa is the electric field slope (ESLI) and the ordinate is the synchronous phase slope (PSLT). A combination of ESLI and PSLI below the $98 \%$ curve gives a capture efficiency $\geqslant 98 \%$. It actually is possible to obtain $100 \%$ capture efficiency, as shown in Fig. 3. Any combination of ESLI and PSLI on the $1.0 \mathrm{~m}$ curve gives the same length $(1.0 \mathrm{~m})$ and accelerates the proton from $50 \mathrm{keV}$ to $1 \mathrm{MeV}$. The longer the length is, the better the capture effic.ency is. In the case of $\mathrm{PHI}=0 \mathrm{~cm}$, the capture efficiency curves are rather flat for large ESLI values., These curves imply that the maximum field EUL is applied at injection.

Profile displays are shown in Fig. 8 for selected points from Fig. 5, and in Fig. 9 for points from Fig. 6. The 40-cm bunching length is too long to accelerate the protons to $1 \mathrm{MeV}$ in the $1-\mathrm{m}$ length, see Fig. 7.

We will study these values further with the PARMILA computer code, which includes transverse-oscillation and space-charge approximations. Cell 


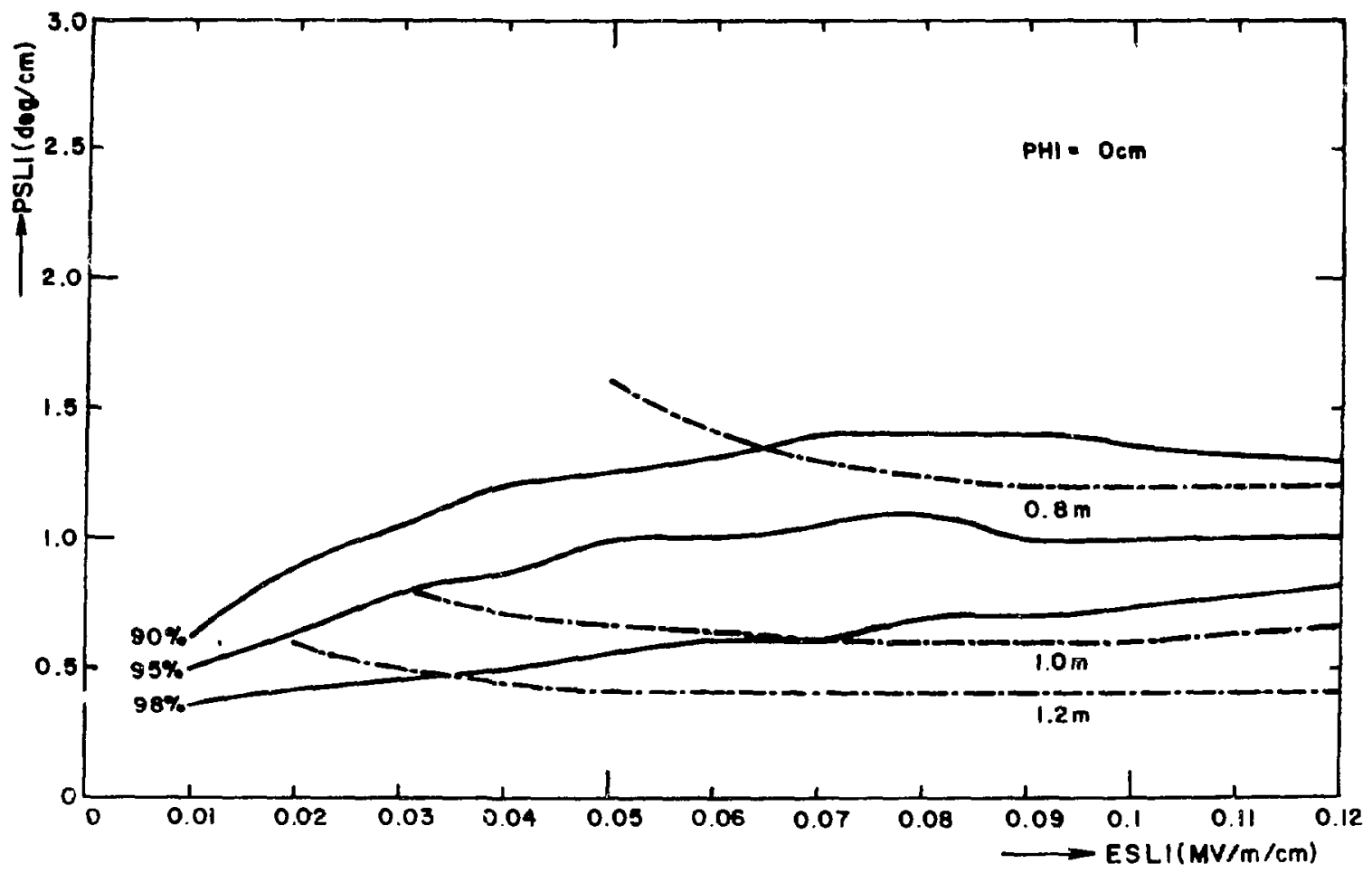

Fig. 5. Capture efficiency-length characteristics for PHI $=0 \mathrm{~cm}$.

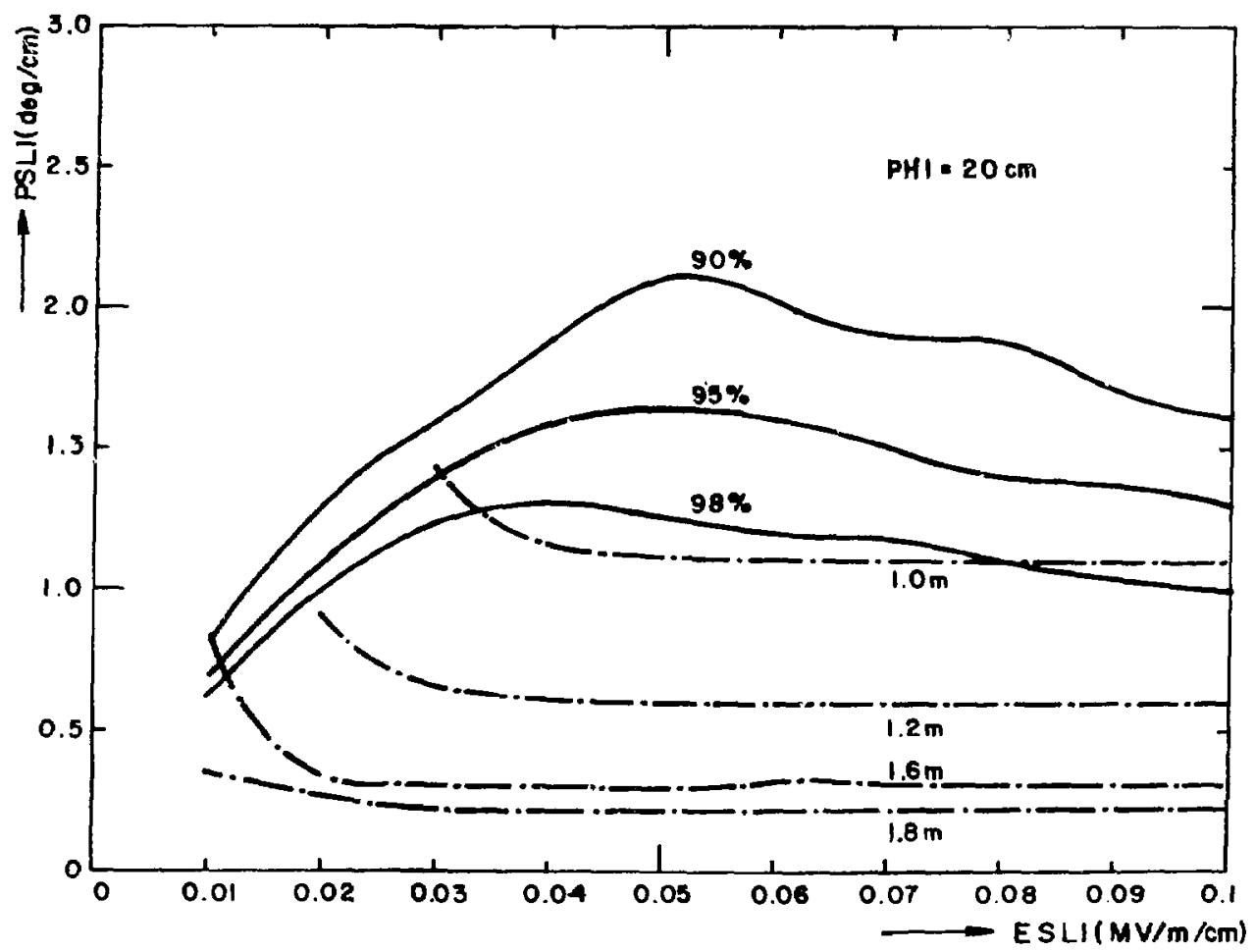

Fig. 6. Capture efficiency-length characteristics for PHI $=20 \mathrm{~cm}$. 


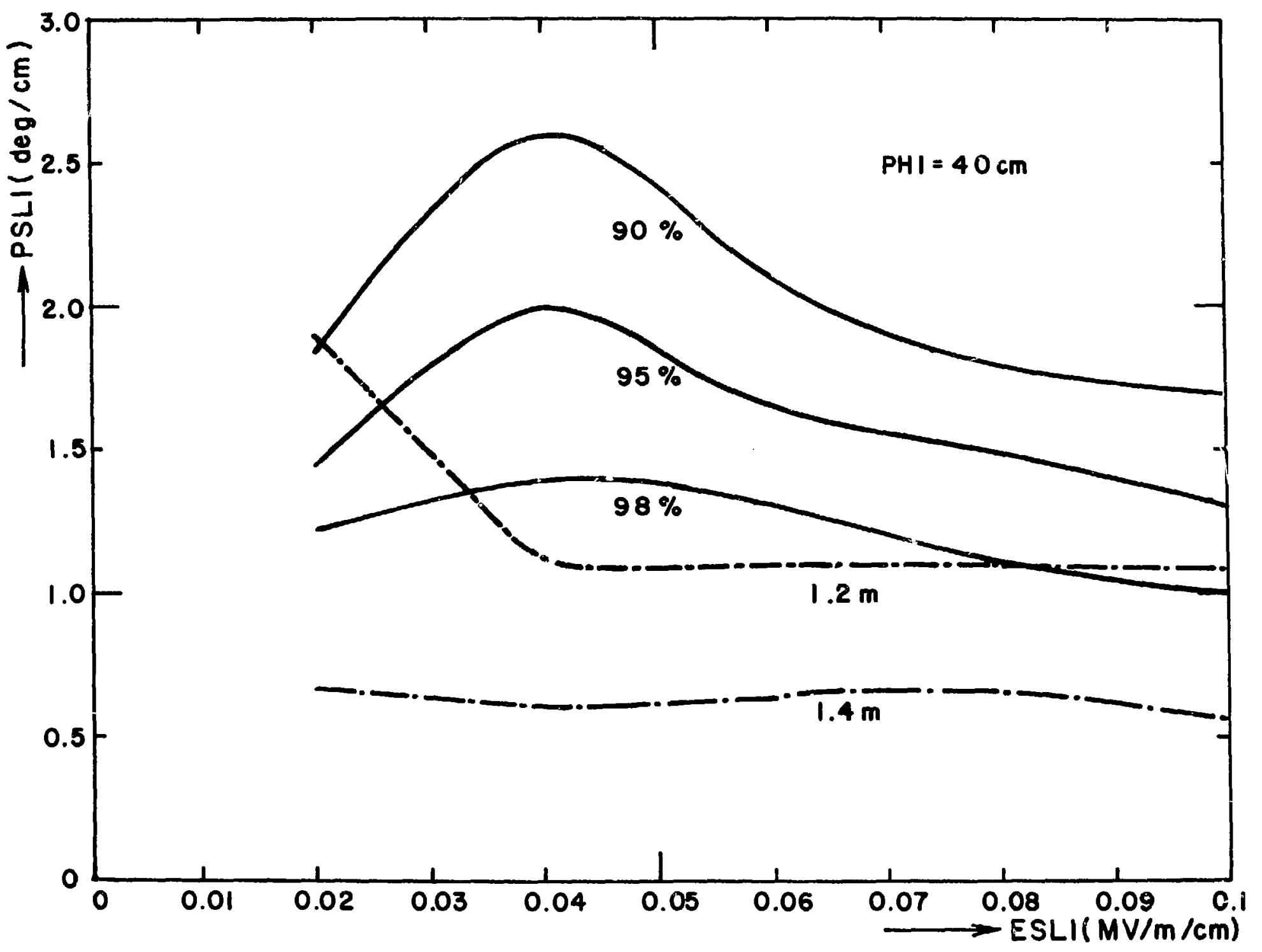


PRU. $1.09 B$ FREQ 440.0 UZ. .050 UF- 1.000 $\begin{array}{llllll}0.0000 & 0.0000 & .0860 & 2.0000 & 0.000-90.000 & .600-30.000\end{array}$ NP. $O$ NG. 2 KG= 2

KH=800 KU.600 PP. 360.0 WW. .2

$\begin{array}{lllllll}\text { CAPTURE } & .475 & .789 & .950 & .978 & .989 & .989\end{array}$

PBAR, UBAR= -26.682

PRMS, URMS- 24.983

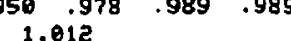

1.012
.023

ESLI, PSLI= $\quad .080 \quad .600$
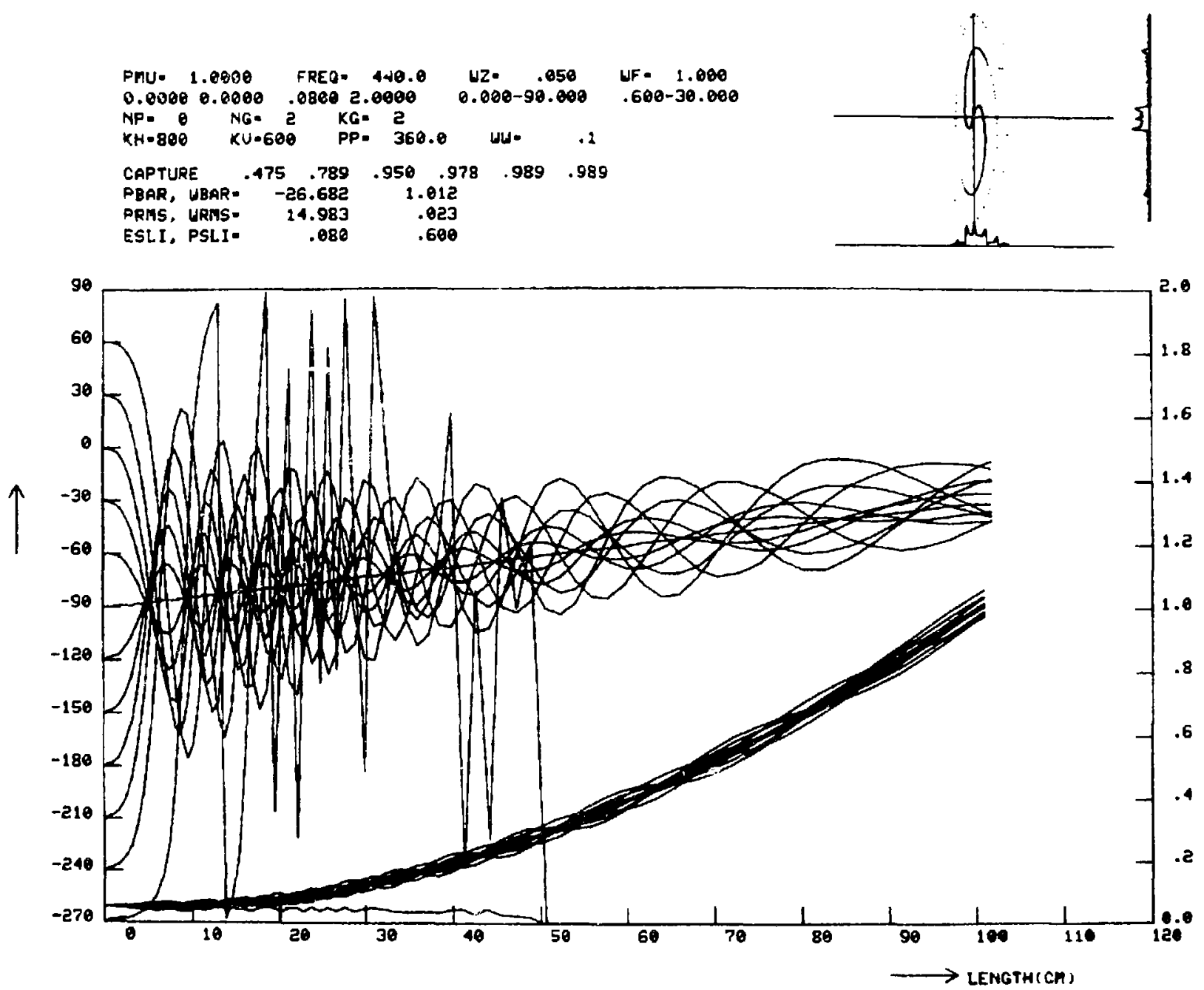

Fig. 8a. Phase oscillation near the optimized region for PHI $=0 \mathrm{~cm}$. 


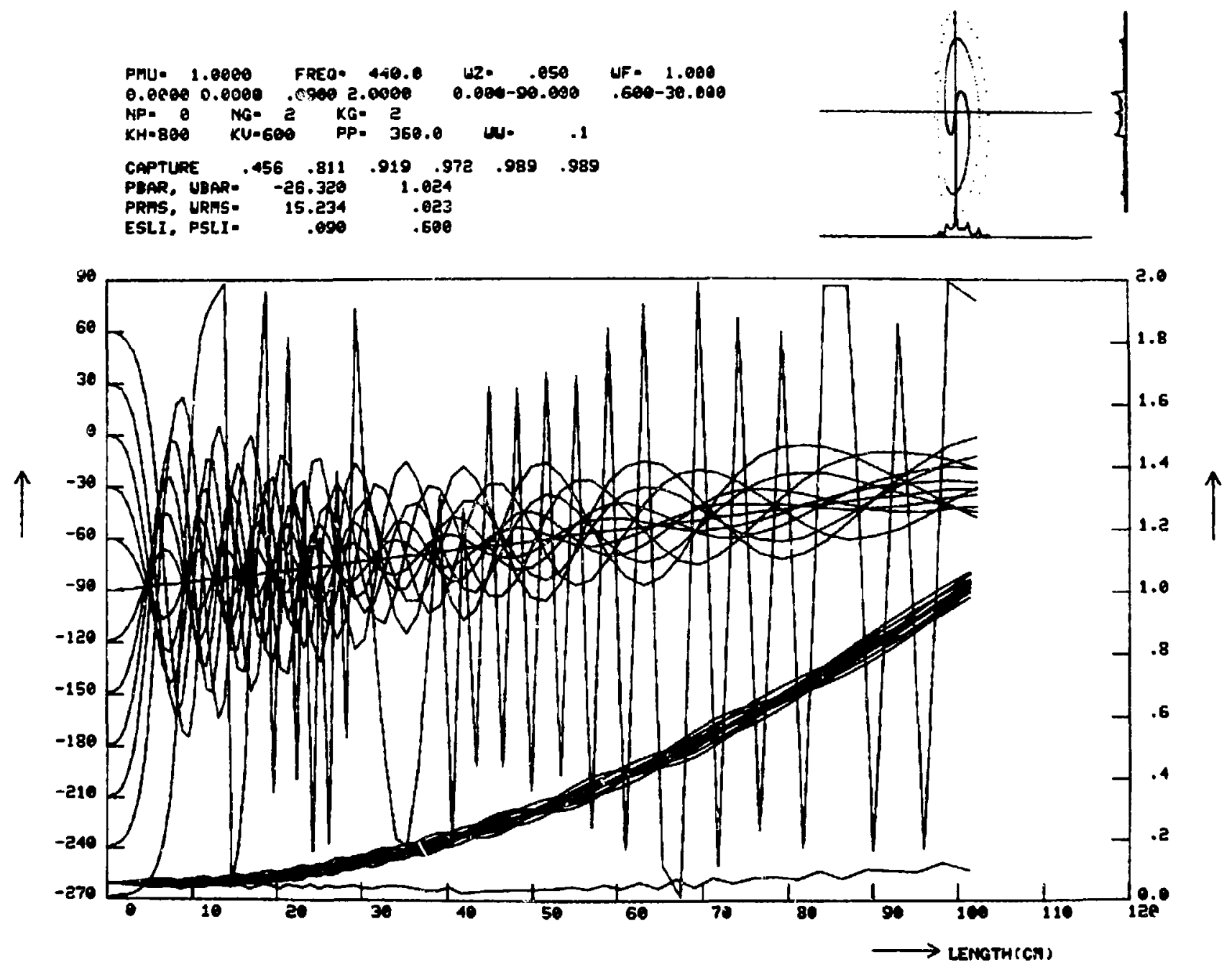


PMU. 1.0000 FREO- $440 . \mathrm{C}$ WZ $=.050$ WF 1.000 $\begin{array}{llllllll}0.0000 & 0.0000 & .1000 & 2.0000 & 0.009-90.000 & .600-30.000\end{array}$ NP. 0 HG. 2 KG. 2

KH.800 KU.600 PP. 360.0 UU. .1

$\begin{array}{llllllll}\text { CAPTURE } & .461 & .800 & .917 & .969 & .992 & .992\end{array}$

PBAR, WBAR- $-26.269 \quad 1.000$

PRMS, WRMS. $15.740 \quad .024$

$\begin{array}{rrr}\text { PRMS. WRHS. } & 15.740 & .624 \\ \text { ESLI. PSLI. } & .100 & .600\end{array}$

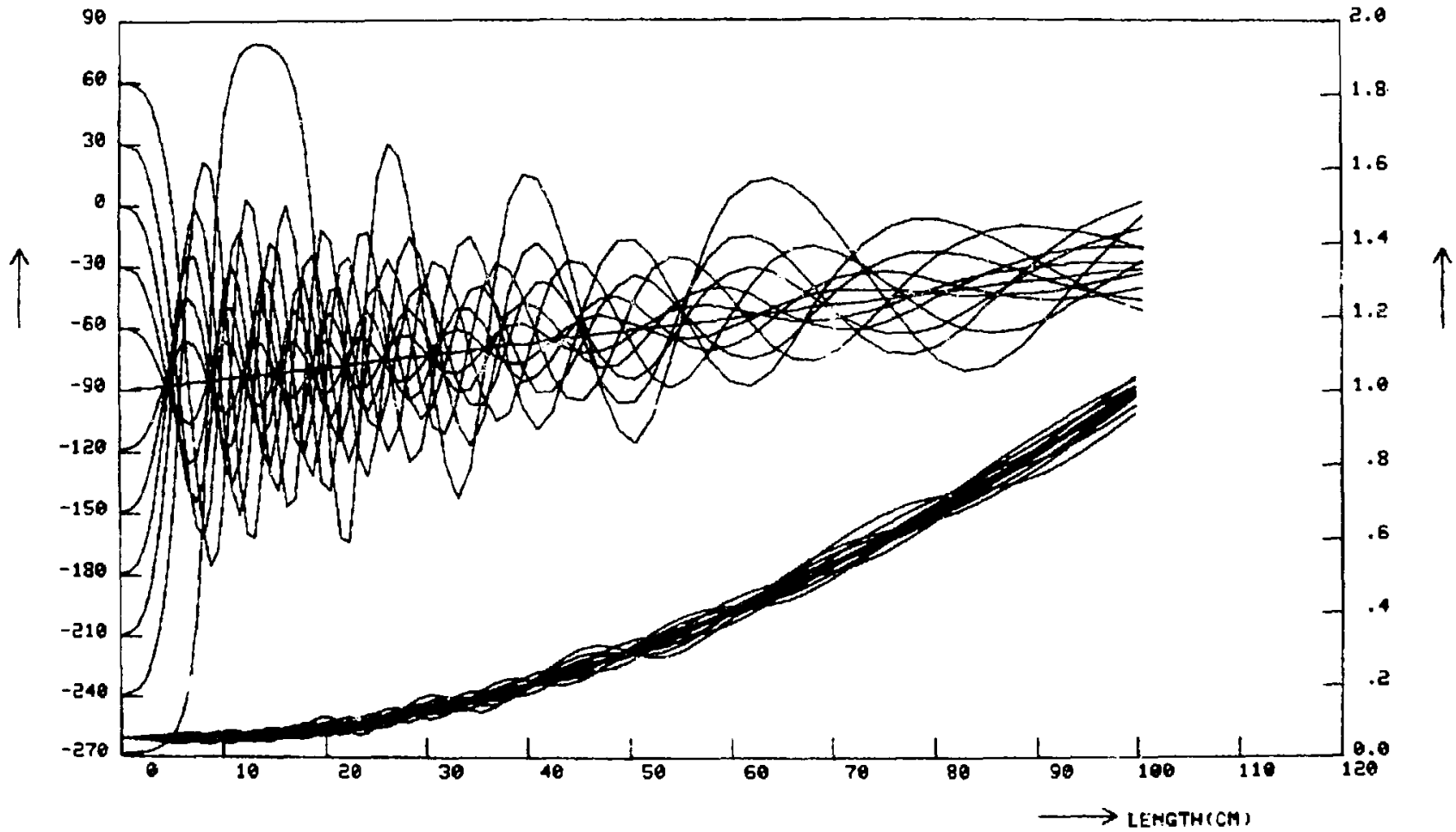

Fig. 8c. Phase oscillation rear the optimized region for PHI $=0 \mathrm{~cm}$. 


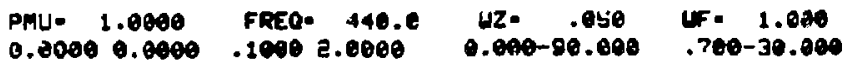

HP. 0 HG. 5 KG.

$K H-800 \quad K U=600$ PP. 350.0 WW. .1

$\begin{array}{lllllll}\text { CAPTURE } & .433 & .783 & .889 & .053 & .975 & .981\end{array}$

PBAR. UBAR- -25.715

PRMS. WRMS. 16.753

ESLI, PSLI -

1.004

.700
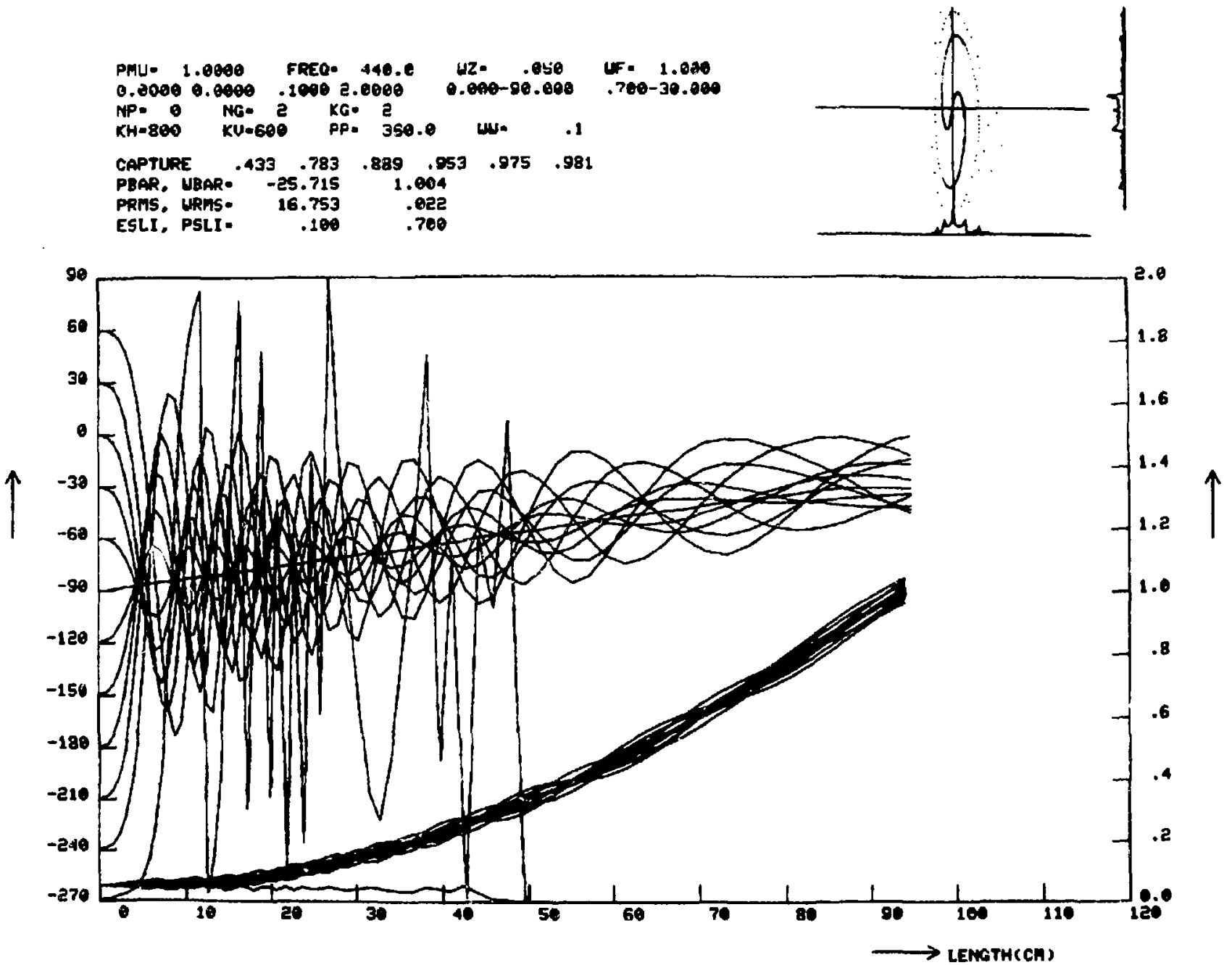

Fig. 8d. Phase oscillation near the optimized region for $\mathrm{PHI}=0 \mathrm{~cm}$. 


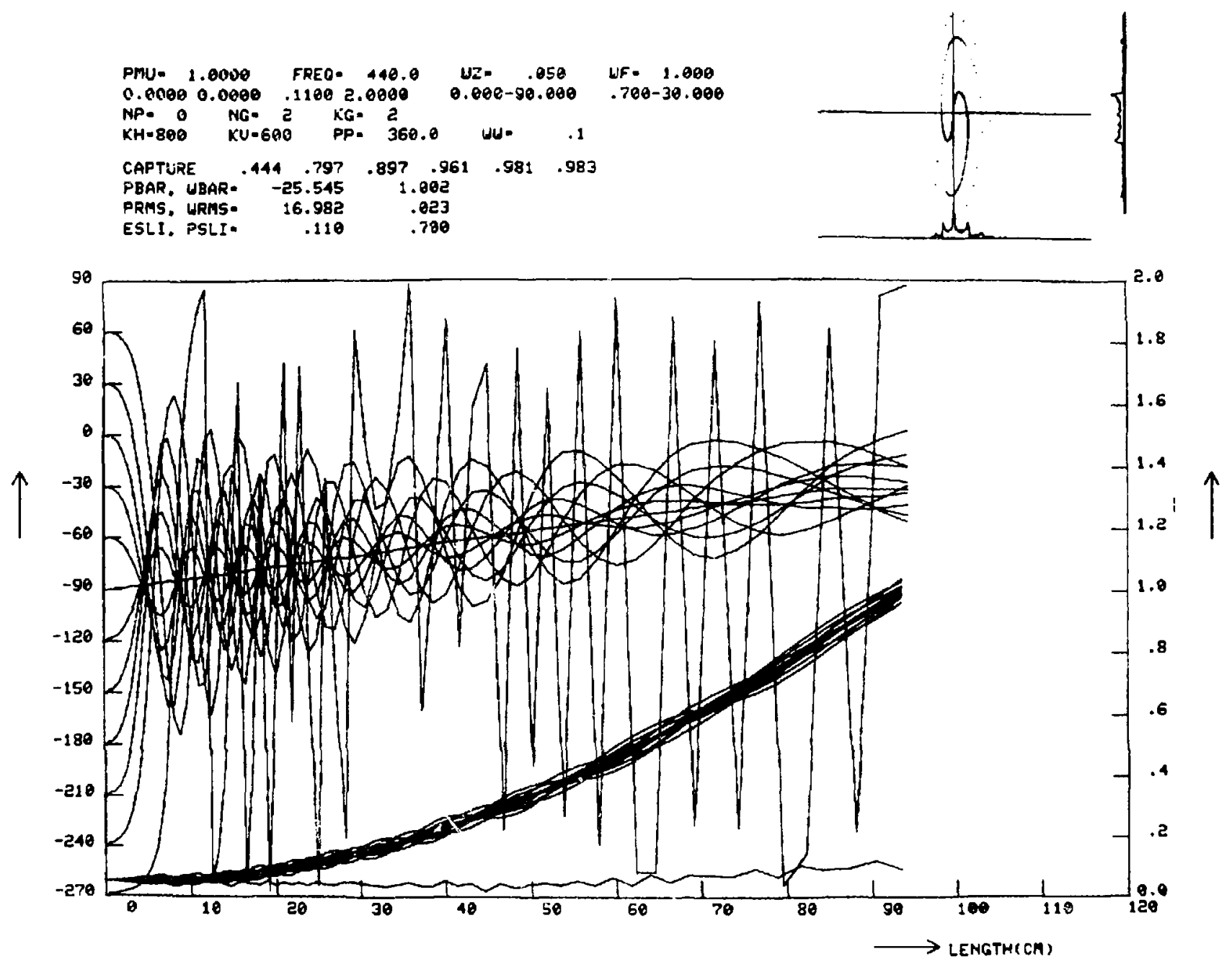

Fig. 8e. Phase oscillation near the optimized region for $\mathrm{PHI}=0 \mathrm{~cm}$. 
PNU. 1.0000 FREO- 440.0 UZ. .050 UF- 1.000 $0.0000 \quad 0.0000 \quad .1200 \quad 2.0000 \quad 0.000-90.000 \quad .600-30.000$ NP. 0 NG- 2 KG 2

KH-800 XU-600 PP. 360.0 WL- .1

$\begin{array}{lllllll}\text { CAPTURE } & .506 & .756 & .911 & .969 & .992 & .992\end{array}$

PBAR, WBAR: $-25.987 \quad 1.016$

PRMS, WRMS- $16.044 \quad .025$
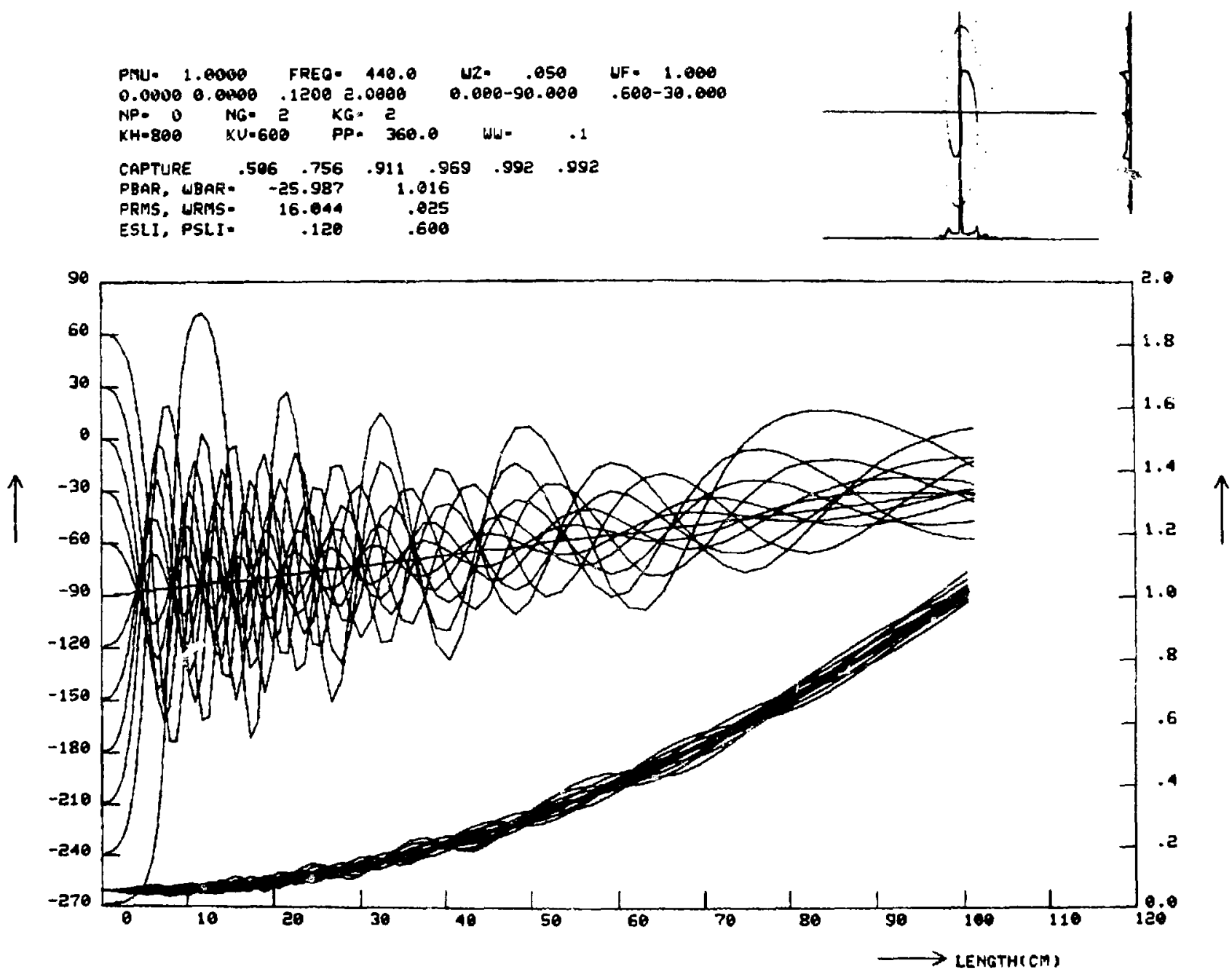


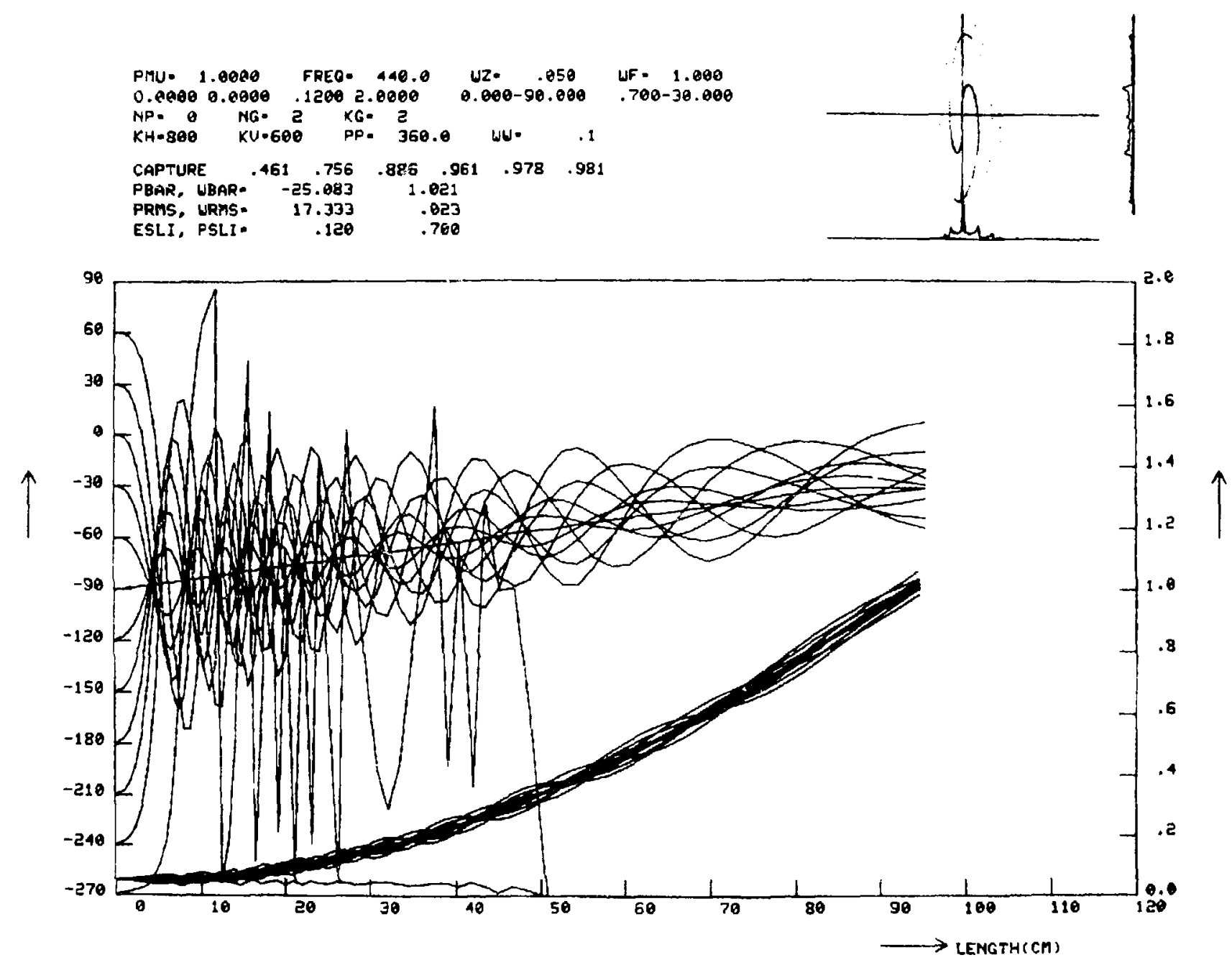

Fig. 8g. Phase oscillation near the optimized region for $\mathrm{PHI}=0 \mathrm{~cm}$. 
PMU. 1.0000 FREG. 440.0 UZ. .050 UF. 1.000

$0.09000 .0000 \quad .03502 .0000 \quad 20.006-90.000 \quad .100-30.000$

NP. $\theta$ NG. 2 KG.

$K H+800 \quad K U=600$ PP. 360.0 WH.

$\begin{array}{lllllll}\text { CAPTURE } & .589 & .831 & .936 & .981 & .981 & .983\end{array}$

PBAR, UBAR= -25.056 1.009

PRMS, URMS. $17.565 \quad .024$

ESLI. PSLI. $\quad .035 \quad 1.200$
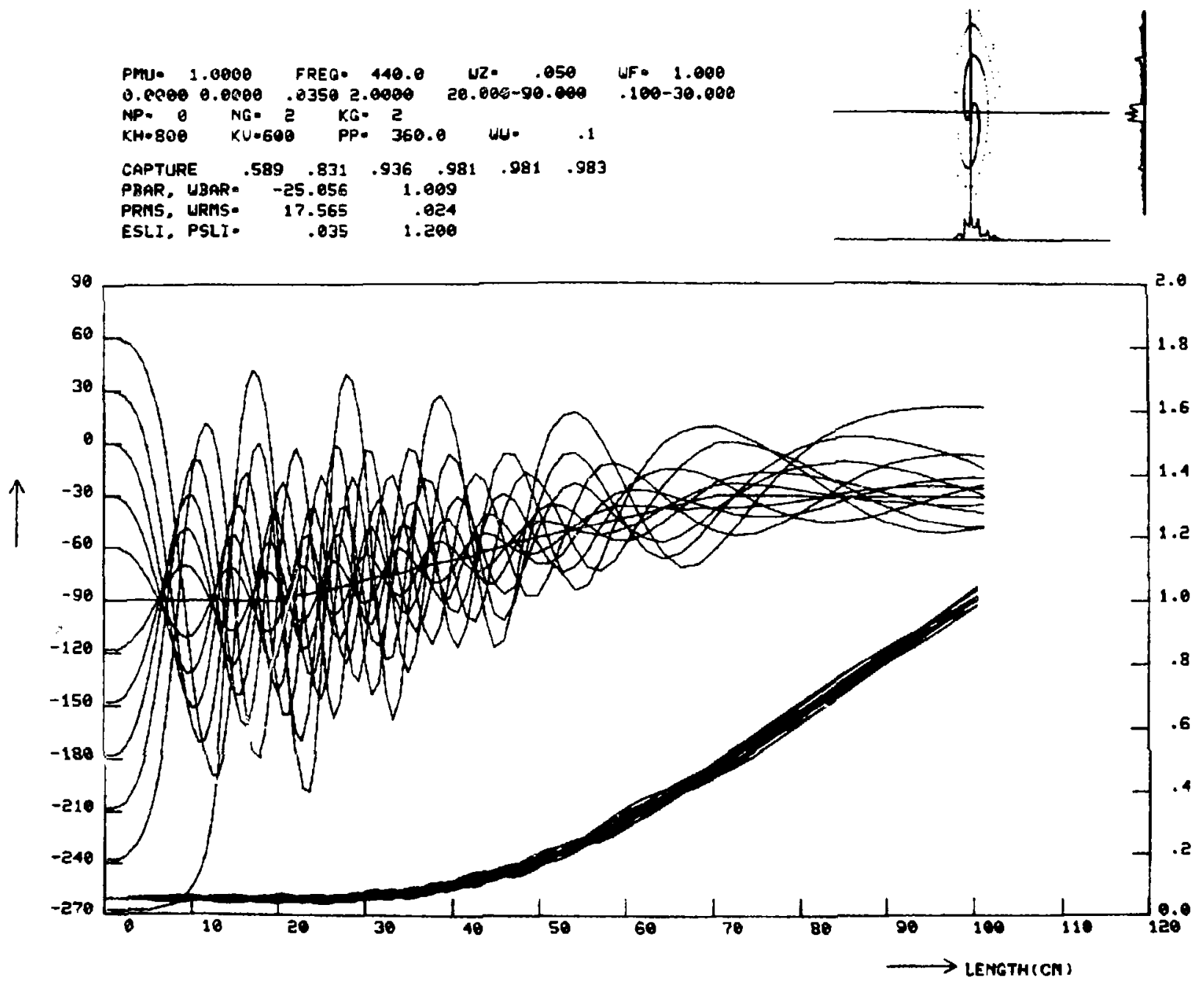

Fig. 9a. Phase oscillation near the optimized region for $\mathrm{PHI}=20 \mathrm{~cm}$. 
PMU 1.0000 FREQ 440.0 WZ $=.050$ UF $=\{.000$ $0.0000 \quad 0.0000 \quad .01002 .0000 \quad 20.000-90.000 \quad .100-30.000$ MP. $O$ NG. 2 KG. 2

KH=800 XU-600 PP. 360.0 UU. .1

$\begin{array}{lllllll}\text { CAPTURE } & .525 & .836 & .936 & .961 & .973 & .978\end{array}$

PBAR, WBAR" $-24.805 \quad 1.023$

$\begin{array}{rrr}\text { PRAS, LRAS. } & 16.613 & .021 \\ \text { ESLI. PSLI. } & .040 & 1.200\end{array}$
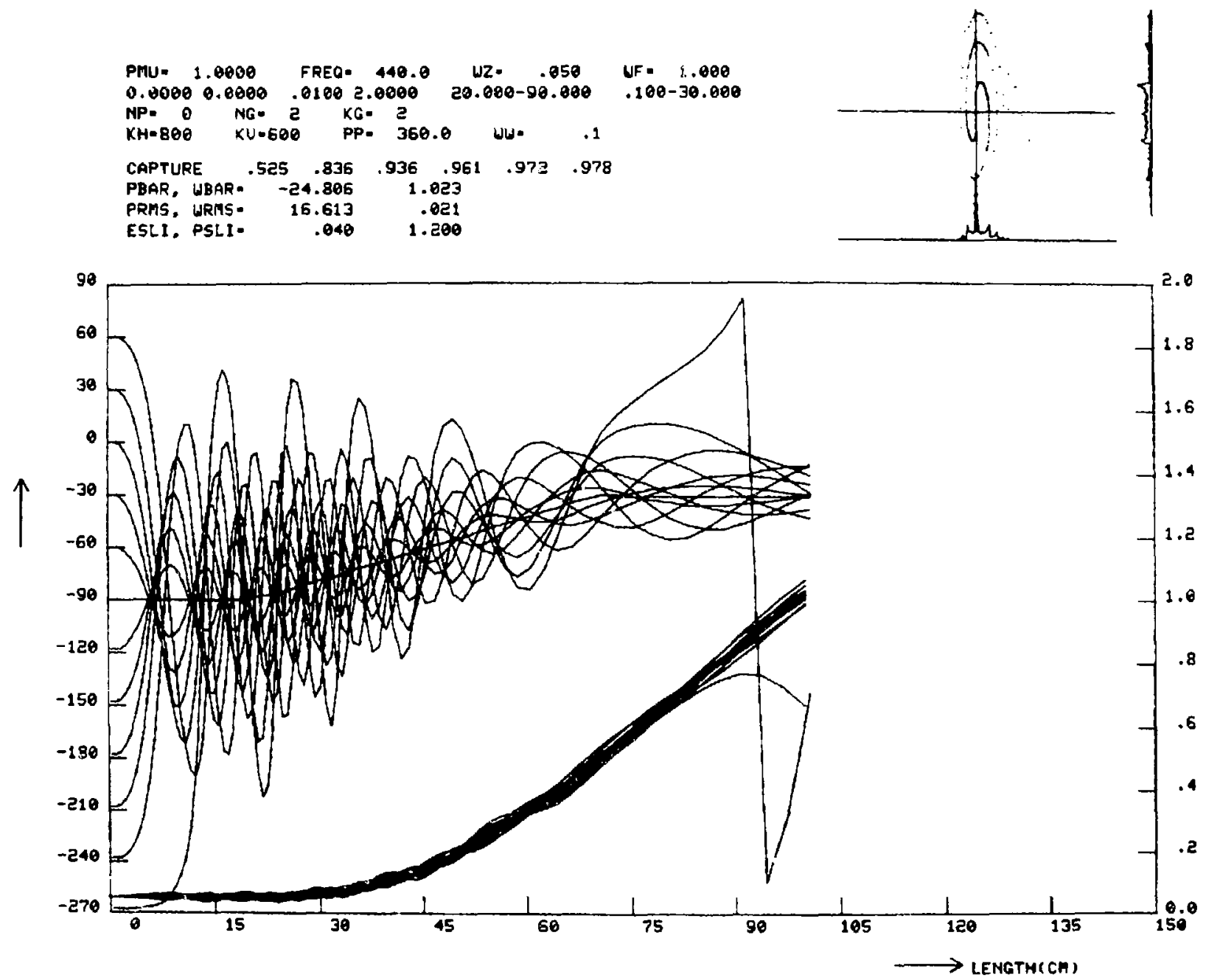

Fig. 9b. Phase oscillation near the optimized region for PHI $=20 \mathrm{~cm}$. 
PNU. 1.000 FREO. 440.0 UZ. .050 UF. 1.000

$0.0000 \quad 0.0000 \quad .04502 .0000 \quad 20.000-96.000 \quad 1.180-30.000$

NP.

KH-800 KU.600 PP. 360.0 WU. .1

$\begin{array}{lllllll}\text { CAPTURE } & .514 & .817 & .928 & .967 & .989 & .989\end{array}$

PBAR, UBAR= $-24.439 \quad 1.025$

PRMS, URMS- $17.060 \quad .023$

ESLI, PSLI $\quad$.045 1.208
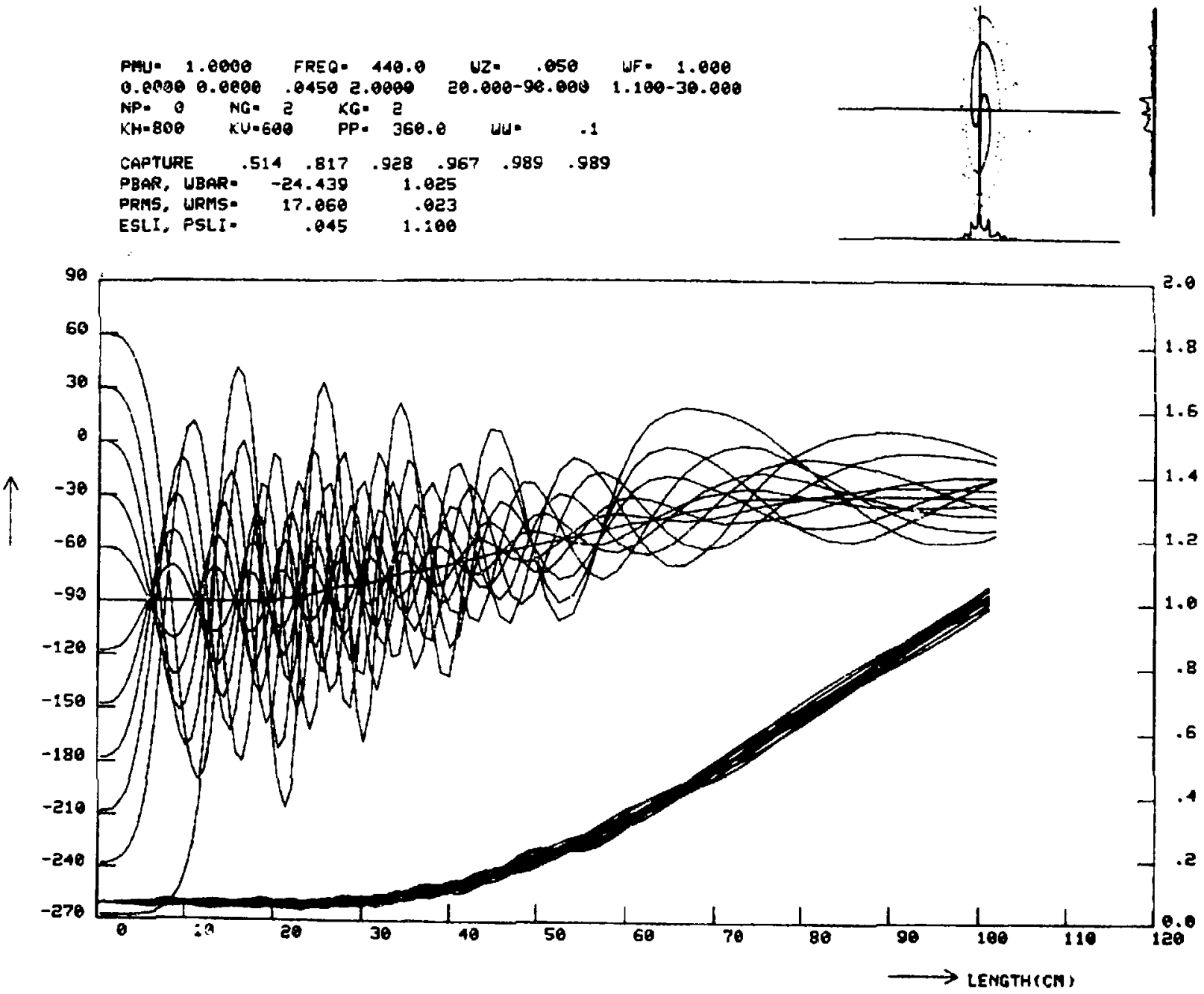


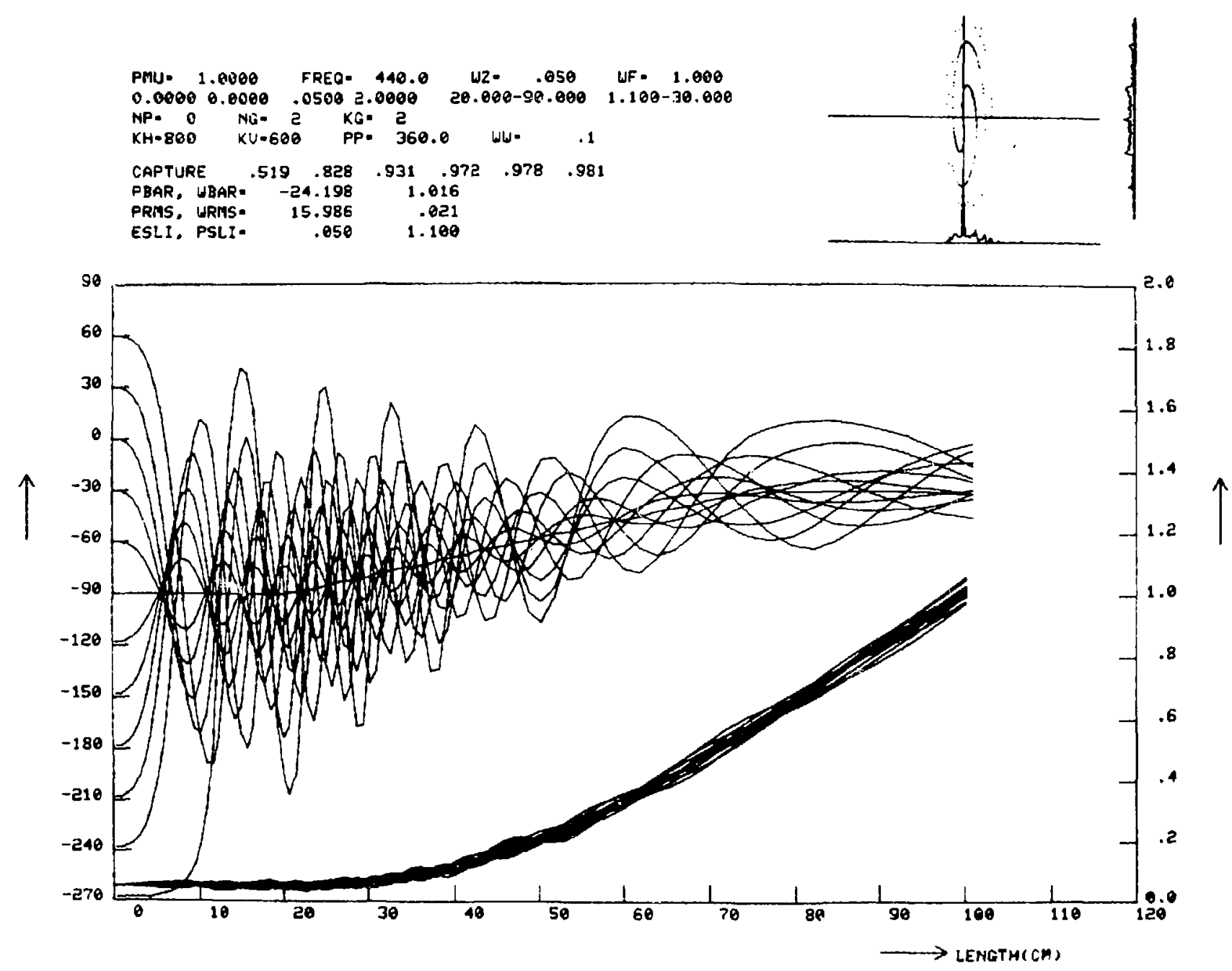

Fig. 9d. Phase oscillation near the optimized region for $\mathrm{PHI}=20 \mathrm{~cm}$. 
PMU. 1.0800 FREO. 440.0 UZ. .050 UF 1.000 $\begin{array}{llllll}0.0000 & 0.0000 & .0100 & 2.0000 & 20.000-90.000 & .100-30.090\end{array}$ NP. O NG. 2 KG.

KH.800 KU.600 PP. 360.0 H. .I

$\begin{array}{llllllll}\text { CAPTURE } & .567 & .806 & .911 & .950 & .972 & .981\end{array}$

PBAR, UBAR = $-24.040 \quad 1.028$

PRMS, URMS- $18.483 \quad .025$

ESLI, PSLI. $\quad .050 \quad 1.200$
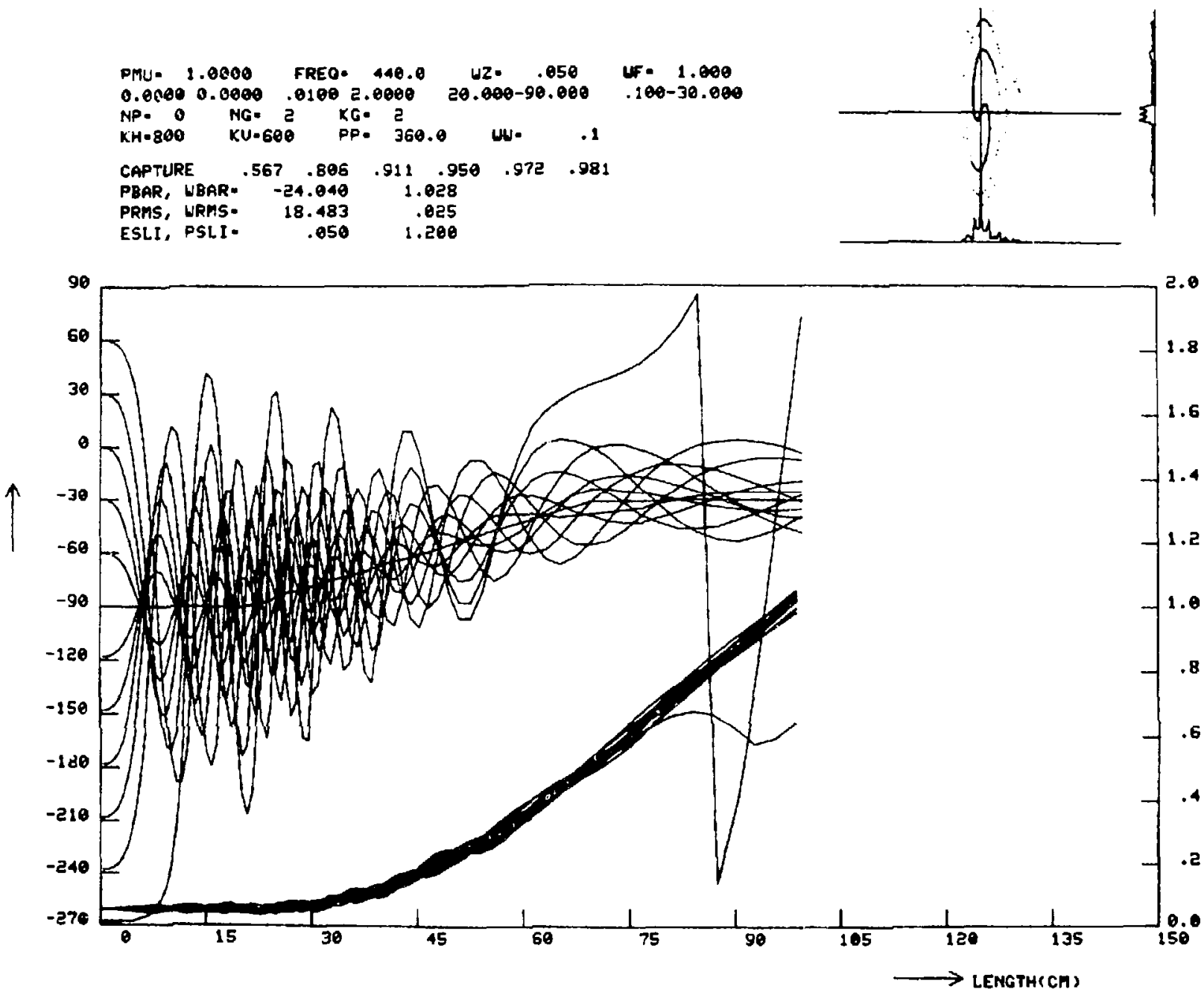


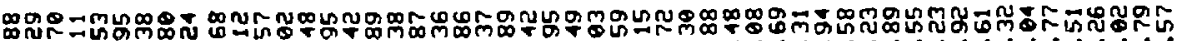

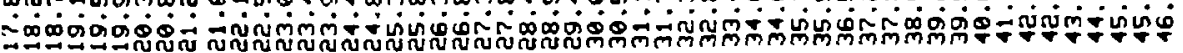

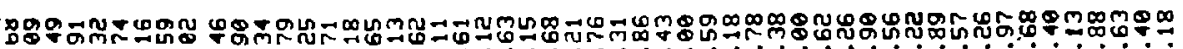

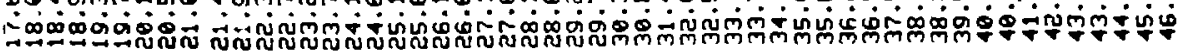

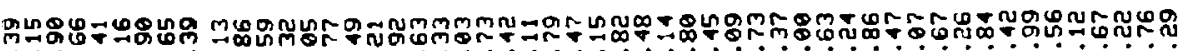
कón

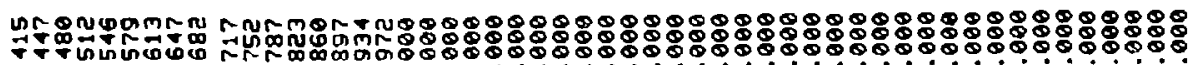

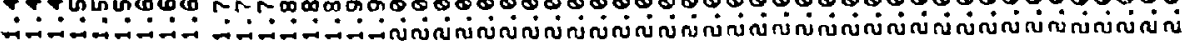

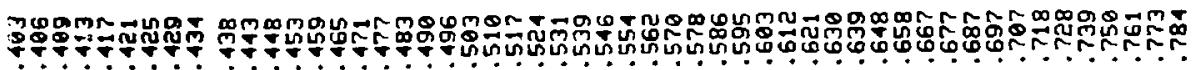

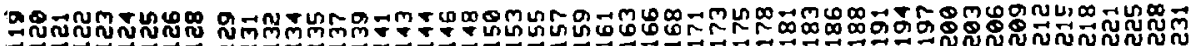

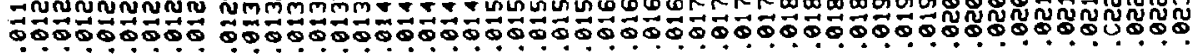

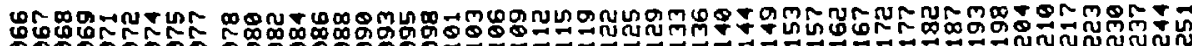

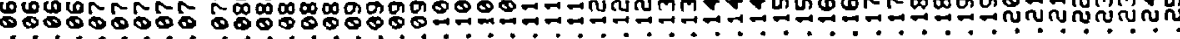

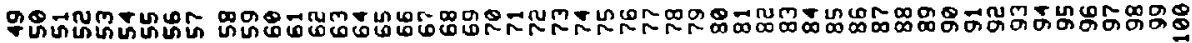

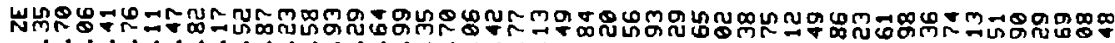

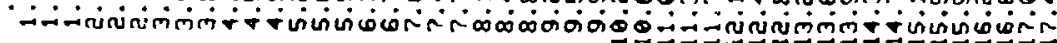

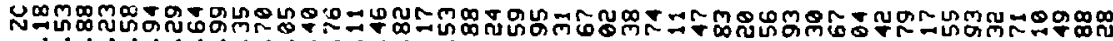

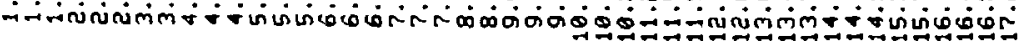

แำ

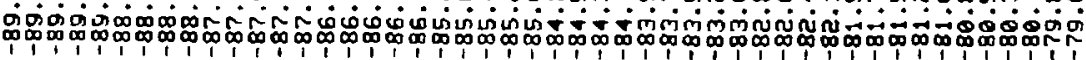

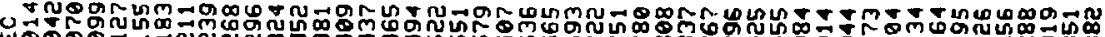

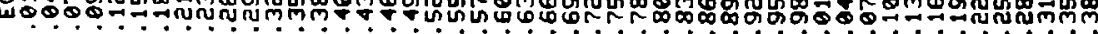

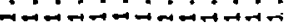

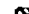

تํํำน

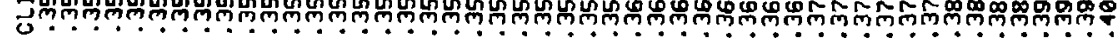

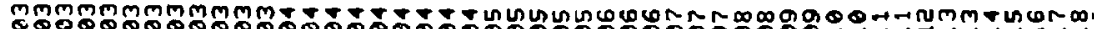

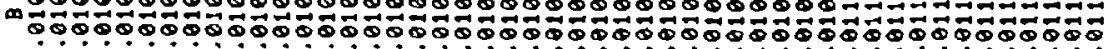

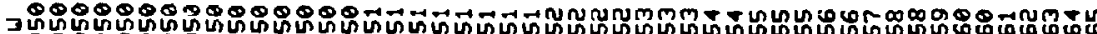
Q.0\%

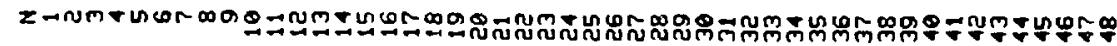


TABLE I (cont)

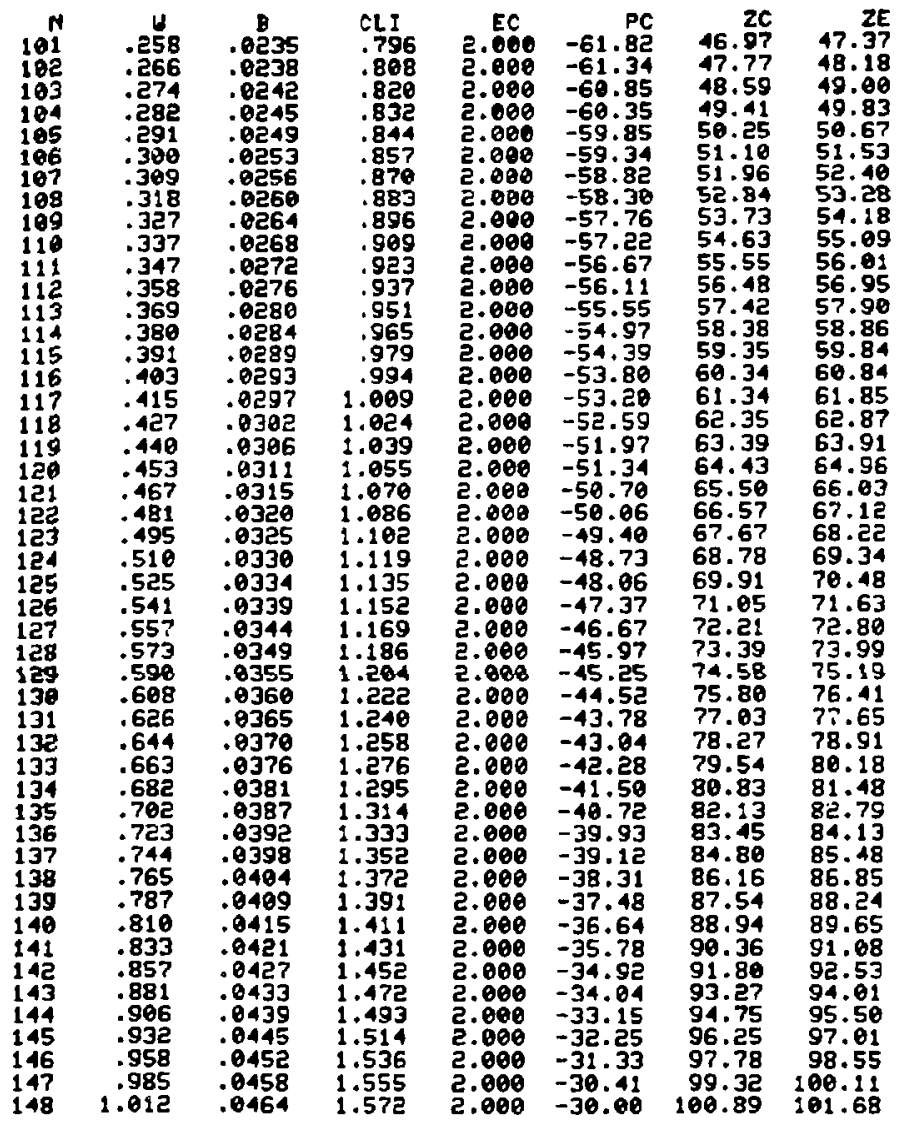

dimensions for a typical case ave shown in Table $I$ where PHI $=0 \mathrm{~cm}$, ESLI = $0.08 \mathrm{MV} / \mathrm{m} / \mathrm{cm}$, and PSLI $=0.6^{\circ} / \mathrm{cm}$.

\section{CONCLUS ION}

Longitudinal oscillation studies were made of particles with low beta and 1 ow rigidity. To our surprise, $100 \%$ capture efficiency is easi1y attained, and the $98 \%$ region is rather wide. However as the cell's size becomes rather sma11, the bore diameter also decreases. Thus, a study to determine space-charge effects will be necessarv. 


\section{ACKNOWLEDGMENTS}

I am very much indebted to $\mathrm{Dr}$. Swenson for suggesting this study. Also I thank T. Wangler, IASI, Group AT-I, for discussing the interpretation of the Kapchinskii-Teplyakov formulation. Discussions with J. Potter, R. Stokes, K. Cranda11, LASL Group AT-1, and S. Williams, HEDL, were al so encouraging. The authors wishes to express his sincere thanks to all AT-1 group members, E. Knapp, and R. Jameson of the LASL Accelerator Division Office for their hospitality during my stay in LASL. I also wish to thank S. O. Schriber of the Chalk River Nuclear Laboratories, Canada, for his help. My stay at LASL was made possible by a grant from the Yoshida Foundation of Science and Technology, Tokyo, Japan.

\section{REFERENCES}

1. Ia. B. Fainberg, "Alternating Phase Focusing," CERN Symposium 11 (1956).

2. D. A. Swenson, "Alternating Phase Focused Linacs," Part. Accl. 7, 61 (1975).

3. G. M. Anisimov and V.A. Teplyakov, "Focusing by an Accelerating Field," Pribory i Tekhnika Eksperimenta 1, 21 (1963).

4. F. Fer, P. Lapostolle, C. Bieth, A. Cabrespine, "Cross-Gradient Focusing in Linear Accelerators," Proc. Int. Conf. High Energy Accelerators, Dubna, USSR (1963).

5. I. M. Kapchinskii and V. A. Teplyakov, "Linear Ion Accelerator with Spatially Homogeneous Strong Focusing," Pribory i Tekhnika Eksperimenta 2, $19(1970)$.

6. I. M. Kapchinskii, "Ion Linear Accelerator with Strong High-Frequency Focusing - Beam Dynamics in the Section with Spatially "niform Focusing Part I," Serpukhov Institute for High Energy Physics report IHP-INZH 72-29 (1972).

7. I. M. Kapchinskii, "Linear Ion Accelerator with Kigh-Frequency Strong Focusing: Dynamics of the Beam in Sections with Spatially homogeneous Focusing: Part 2," Los Alamos Scientific Laboratory translation LA-TR-79-4 (1979).

8. B. L. Ioffe, I. M. Kapchinskii, N. V. Lazarev, A. D. Leongardt, I. V. Chuvilo and R. G. Vasilkov, "The 3 cheme of a $14 \mathrm{MeV}$ Intensive Neutron Generator with a Two Frequency Deuteron Linac," Moscow Institute of Theoretical and Experimental Physics report ITEP-118 (1977). 
9. B. M. Gorshkov, S. A. Ilevskii, G. M. Kolomenskii, S. P. Kuznetsov, N. N. Kutorga, A. P. Maltsev, I. G. Maltsev, K. G. Merzoev, V. B. Stepanov, V. A. Tepljakov, and I. M. Shalashov, "Startup of the URAL-15 Linear Proton Accelerator with Quadrupole rf Focusing," Sov. Phys. Tech. Phys. 221348 (1977).

10. R. A. Jameson and F. Stagnaro, "Workshop Notes--HEDL Frequency Choice Workshop, April 12-13, 1978, Los Alamos Scientific Laboratory internal memorandum (April 1978).

11. R. Jameson, "High Intensity Deuteron Linear Accelerator (FMIT)," IEEE Trans. Nucl. Sei. NS-26, No. 3, pp. 2896-2991 (June 1979).

12. R. H. Stokes, K. R. Cranda 11, J. E. Stova 11 , and D. A. Swenson, "RF Quadrupole Beam Dynamics," IEEE Trans. Nuc1. Sci. NS-26, No. 3, pp. 3469-3471 (June 1979).

13. J. M. Potter, S. W. Williams, F. J. Humphry and G. W. Rodenz, "Radio Frequency Quadrupole Accelerating Structure Research at Los Alamos," IEEE Trans. Nuc1. Sci. NS-26, No. 3, pp. 3745-3750 (June 1979).

14. K. Batchelor, R. Chasmnan, and N. Fewe 11, "Calculation and Measurements on on Reduction of the Energy Spread and the Variation in Mean Energy of the $200 \mathrm{MeV}$ Linac Beam at Brookhaven," Los Alamos Scientific Laboratory report $L A-5115(1972)$.

15. G. W. Wheeler, "Performance of the BNL 200-MeV Proton Linear Accelerator," in Proc. U. S. and Japan Seminar on High-Energy Accelerator Science, Tokyo and Tsukube, 269 (1973).

16. H. Matsumoto, J. Tanaka, I. Sato, S. Okumura, and S. Inagaki, "Synchronous Phase Low Experiment in the KEK Linac," KEK-77-3 (1977). 